\title{
Bioavailability and Pharmacokinetics of Once-Daily Amantadine Extended-Release Tablets in Healthy Volunteers: Results from Three Randomized, Crossover, Open-Label, Phase 1 Studies
}

\author{
Tina deVries $\cdot$ Angela Dentiste $\cdot$ Lata Handiwala $\cdot$ David Jacobs
}

Received: April 26, 2019 / Published online: August 1, 2019

(C) The Author(s) 2019

\section{ABSTRACT}

Introduction: In February 2018, OS320-an amantadine extended-release (ER) tablet formulation with once-daily morning administration-was approved for the treatment of Parkinson's disease and drug-induced extrapyramidal reactions in adults. The purpose of this study was to describe three phase 1 studies that assessed the pharmacokinetics (PK) and bioavailability of amantadine ER in healthy adult volunteers.

Methods: Study 1 was an open-label, fourtreatment, single-dose, crossover study comparing amantadine ER 129, 193, and $258 \mathrm{mg}$ tablets with an equivalent dose of immediaterelease (IR) amantadine $40 \mathrm{mg} / 5 \mathrm{~mL}$ syrup. Study 2 was an open-label, single-dose, crossover food-effect study with amantadine ER $258 \mathrm{mg}$. Study 3 was an open-label, multipledose, crossover study comparing amantadine ER and amantadine IR syrup.

Results: Amantadine ER displayed a steady release of amantadine, with the peak

Enhanced digital features To view enhanced digital features for this article go to https://doi.org/10.6084/ m9.figshare.8332382.

T. deVries · A. Dentiste $\cdot$ L. Handiwala $\cdot$ D. Jacobs $(\triangle)$

Osmotica Pharmaceutical US LLC, Bridgewater, NJ, USA

e-mail: djacobs@osmotica.com amantadine concentration occurring at $\sim 7.5 \mathrm{~h}$ postdose or in the middle of the day (following a morning dose) with steady-state administration. Administration of amantadine ER $258 \mathrm{mg}$ with a high-fat meal did not affect amantadine bioavailability. Amantadine plasma exposure increased proportionally with increasing doses, and at steady state, amantadine exposure from an amantadine ER 258-mg tablet was bioequivalent to twice-daily $129-\mathrm{mg}$ amantadine IR syrup.

Conclusion: The PK profile of amantadine ER 129-mg, 193-mg, and 258-mg tablets allows for once-daily dosing in the morning; the 24-h average amantadine plasma concentration is equivalent to that for the same daily dose of IR amantadine administered twice daily.

Funding: Osmotica Pharmaceutical US LLC.

Keywords: Absorption; Amantadine; Bioavailability; Bioequivalence; Pharmacokinetics

\section{INTRODUCTION}

Amantadine is a weak, uncompetitive antagonist of the $N$-methyl-D-aspartate (NMDA) receptor $[1,2]$. Amantadine hydrochloride $(\mathrm{HCl})$ in an immediate-release (IR) formulation is indicated for the prophylaxis and treatment of infection caused by the influenza A virus, for the treatment of Parkinson's disease (PD), as well as for drug-induced extrapyramidal 
reactions (EPRs; also referred to as extrapyramidal symptoms). Amantadine HCl IR is available as a 100-mg tablet (equivalent to $81 \mathrm{mg}$ base amantadine) and $50 \mathrm{mg} / 5 \mathrm{~mL}$ syrup (equivalent to $40 \mathrm{mg} / 5 \mathrm{~mL}$ base amantadine), and is typically administered twice daily [3].

Due to Food and Drug Administration (FDA) guidelines, unless otherwise stated, all amantadine doses are reported herein as the base dose of amantadine, rather than the equivalent amantadine $\mathrm{HCl}$ dose. Amantadine IR plasma pharmacokinetics were studied in healthy volunteers shortly after its approval in the 1970s. Amantadine is readily absorbed orally and is primarily excreted unchanged in the urine by glomerular filtration and tubular secretion $[1,4,5]$. The antiparkinsonian effect of amantadine is observed within $48 \mathrm{~h}$ following dosage initiation [1]. More recent studies have focused on amantadine pharmacokinetics in specialized populations, including comatose children, PD patients, and the elderly [6-8]. Following oral administration of an 81-mg amantadine IR formulation (equivalent to $100 \mathrm{mg}$ amantadine $\mathrm{HCl})$ twice daily for 5 days in healthy adults, maximum blood levels were $636.2 \mathrm{ng} / \mathrm{mL}$, with the peak concentration occurring $2.1 \mathrm{~h}$ postdose [9].

A once-daily extended-release (ER) formulation of amantadine, OS320 (Osmolex $\mathrm{ER}^{\mathrm{TM}}$ ), was approved by the FDA in February 2018 via the 505(b)(2) regulatory pathway for the treatment of PD and drug-induced EPRs in adults [10]. OS320 is available in strengths of $129-\mathrm{mg}$, 193-mg, or 258-mg amantadine (160, 240, or $320 \mathrm{mg}$ amantadine $\mathrm{HCl}$, respectively) [10]. The approval of OS320 was informed by the bioequivalence it exhibited when compared with amantadine IR. OS320 is not interchangeable with other amantadine IR or ER products. Here, we describe the pharmacokinetics (PK) and bioavailability of amantadine ER tablets in three phase 1 clinical studies in healthy volunteers.

The aim of these three PK studies was to provide a comprehensive assessment of OS320 bioavailability and pharmacokinetics. We hypothesized that OS320 would be absorbed slowly following a single dose, that eating a high-fat meal would not influence OS320 pharmacokinetics, and that OS320 bioavailability is equal to an equivalent daily dose of amantadine IR.

\section{METHODS}

\section{Study Design}

Study 1 was a randomized, open-label, laboratory-blinded, four-treatment, four-period, foursequence, single-dose, crossover study in healthy adult volunteers. Single oral doses of the following four treatments were administered under fasting conditions: (A) amantadine ER tablet, $129 \mathrm{mg}$; (B) amantadine ER tablet, $193 \mathrm{mg}$; (C) amantadine ER tablet, $258 \mathrm{mg}$; and (D) amantadine IR syrup, $40 \mathrm{mg} / 5 \mathrm{~mL}$ (reference treatment). Eligible subjects were randomized to receive the treatments with approximately $240 \mathrm{~mL}$ water in one of four treatment sequences $(\mathrm{ABCD}, \mathrm{BCDA}, \mathrm{CDAB}$, DABC) after an overnight fast. Each treatment period was separated by a washout period of 7 days. See the summary of the study design shown in Table 1.

Study 2 was a randomized, open-label, laboratory-blinded, two-treatment, two-period, twosequence, single-dose, crossover study in healthy adult volunteers. Single oral doses of amantadine ER 258-mg tablets were administered under fasting (reference) and fed (test) conditions. Both treatments were administered after an overnight fast with approximately $240 \mathrm{~mL}$ water. Eligible subjects were randomized to receive the treatments in one of two treatment sequences. The treatment periods were separated by a washout period of 7 days (Table 1).

Study 3 was a randomized, open-label, laboratory-blinded, two-treatment, two-period, twosequence, multiple-dose, crossover study in healthy volunteers. The two treatment groups were amantadine 258-mg ER tablet (258-mg dose once daily for seven consecutive days; Treatment A, test) and amantadine $40 \mathrm{mg} / 5 \mathrm{~mL}$ IR syrup (129-mg dose twice daily for seven consecutive days; Treatment $\mathrm{B}$, reference). Eligible volunteers were randomized to receive the treatments in one of two treatment sequences $(\mathrm{AB}, \mathrm{BA})$. Following a 2-day titration period, 
Table 1 Summary of study design for the three phase 1 trials

\begin{tabular}{|c|c|c|c|}
\hline & Study 1 & Study 2 & Study 3 \\
\hline $\begin{array}{l}\text { Primary } \\
\text { objective }\end{array}$ & $\begin{array}{l}\text { To determine the relative } \\
\text { bioavailability of amantadine } \\
\text { 129-mg ER tablets compared } \\
\text { with the plasma profiles and } \\
\text { pharmacokinetic parameters of a } \\
\text { reference formulation of } \\
\text { amantadine IR syrup ( } 129 \mathrm{mg} \text { ) } \\
\text { after single-dose administration } \\
\text { under fasting conditions }\end{array}$ & $\begin{array}{l}\text { To determine the bioavailability of } \\
\text { amantadine } 258 \text {-mg ER tablets } \\
\text { after single-dose administration } \\
\text { under fasting and fed conditions }\end{array}$ & $\begin{array}{l}\text { To determine the steady-state } \\
\text { relative bioavailability after } \\
\text { multiple-dose administration of } \\
\text { amantadine } 258 \text {-mg ER tablets } \\
\text { compared with an equivalent } \\
\text { daily dose }(258 \mathrm{mg}) \text { of } \\
\text { amantadine IR syrup under } \\
\text { fasting conditions }\end{array}$ \\
\hline $\begin{array}{l}\text { Study } \\
\text { design }\end{array}$ & $\begin{array}{l}\text { Randomized, open-label, } \\
\text { laboratory-blinded, four- } \\
\text { treatment, four-period, four- } \\
\text { sequence, single-dose, crossover } \\
\text { design }\end{array}$ & $\begin{array}{l}\text { Randomized, open-label, } \\
\text { laboratory-blinded, two- } \\
\text { treatment, two-period, two- } \\
\text { sequence, single-dose, crossover } \\
\text { design }\end{array}$ & $\begin{array}{l}\text { Randomized, laboratory-blinded, } \\
\text { two-treatment, two-period, two- } \\
\text { sequence, multiple-dose, } \\
\text { crossover design }\end{array}$ \\
\hline Population & Healthy volunteers & Healthy volunteers & Healthy volunteers \\
\hline $\begin{array}{l}\text { Dosing } \\
\text { regimen }\end{array}$ & Single dose & Single dose & $\begin{array}{l}\text { Multiple dose ( } 2 \text { days of titration } \\
\text { followed by } 7 \text { days of } \\
\text { administration for each } \\
\text { treatment) }\end{array}$ \\
\hline Treatments & $\begin{array}{l}\text { A. Amantadine ER tablet, } 129 \mathrm{mg} \\
\text { B. Amantadine ER tablet, } 193 \mathrm{mg} \\
\text { C. Amantadine ER tablet, } 258 \mathrm{mg} \\
\text { D. Amantadine IR syrup, } \\
40 \mathrm{mg} / 5 \mathrm{~mL}(129 \mathrm{mg})\end{array}$ & $\begin{array}{l}\text { A. Amantadine ER tablet, } 258 \mathrm{mg} \\
\text { (fasting) } \\
\text { B. Amantadine ER tablet, } 258 \mathrm{mg} \\
\text { (with food) }\end{array}$ & $\begin{array}{l}\text { A. Amantadine ER tablet, } 258 \mathrm{mg} \\
\text { once daily for } 7 \text { days } \\
\text { B. Amantadine IR syrup, } \\
40 \mathrm{mg} / 5 \mathrm{~mL} \text { ( } 129 \text {-mg dose twice } \\
\text { daily for } 7 \text { days) }\end{array}$ \\
\hline
\end{tabular}

$E R$ extended-release, $I R$ immediate-release

treatments were administered on days 3 through 9 (treatment period 1) and days 18 through 24 (treatment period 2). Each treatment period was separated by a washout period of 7 days (Table 1 ).

These studies have not been registered per FDA guidelines that state registration of phase 1 studies is not required.

\section{Compliance with Ethical Standards}

All studies were conducted in accordance with Good Clinical Practice as defined by the International Conference on Harmonisation, the Declaration of Helsinki, and in accordance with the ethical principles underlying European Union Directive 2001/20/EC and the United States Code of Federal Regulations, Title 21, Part 50 (21CFR50). Studies 1 and 3 received ethics committee approval from IRB Services (Aurora, Ontario, Canada). Study 2 received approval from the Optimum Ethics Review Board (Oshawa, Ontario, Canada). All participants provided written informed consent before study participation.

\section{Materials}

Amantadine ER tablets, $129 \mathrm{mg}$ (study 1: Osmotica Pharmaceutical Corp., batch number 
1408001A); amantadine ER tablets, $193 \mathrm{mg}$ (study 1: Osmotica Pharmaceutical Corp., batch number 1408002A); amantadine ER tablets, $258 \mathrm{mg}$ (all studies: Osmotica Pharmaceutical Corp., batch number 1408003A); and amantadine IR syrup, $40 \mathrm{mg} / 5 \mathrm{~mL}$ (studies 1 and 3: Morton Grove Pharmaceuticals, Inc., batch number UQ1262).

\section{Study Population}

In all studies, healthy volunteers-as determined by medical history, physical examinations, vital signs, 12-lead electrocardiograms, and clinical laboratory tests-were eligible to enroll if they were between 18 and 55 years of age, with a body mass index of $18-32 \mathrm{~kg} / \mathrm{m}^{2}$ in study 1 and study 3 and of $18.5-29.9 \mathrm{~kg} / \mathrm{m}^{2}$ in study 2. Exclusion criteria included lactating female subjects; history of hypersensitivity to amantadine or related drugs; history or evidence of psychiatric, cardiac, pulmonary, gastrointestinal, endocrine, musculoskeletal, neurological, hematological, immunological, hepatic, or renal disease, or malignancies; and positive screening of alcohol and/or drugs of abuse.

\section{Sample Collection and Bioanalytical Methods}

In study 1, 28 blood samples were collected serially up to $72 \mathrm{~h}$ postdose from each subject in each treatment period to determine the amantadine plasma concentration and for PK analysis. The plasma samples were assayed for amantadine using a validated high-performance liquid chromatography method with tandem mass spectrometry detection (LC/MS/MS) (Algorithme Pharma, Quebec, Canada). The lower and upper limits of quantitation were $2 \mathrm{ng} / \mathrm{mL}$ and $2000 \mathrm{ng} / \mathrm{mL}$, respectively.

In study 2, 22 blood samples were collected serially up to $72 \mathrm{~h}$ postdose from each subject in each treatment period. The plasma samples were assayed for amantadine using a validated LC/MS/MS method for amantadine (Lambda Therapeutic Research Inc., Toronto, Canada).
The lower and upper limits of quantitation were $2 \mathrm{ng} / \mathrm{mL}$ and $1501 \mathrm{ng} / \mathrm{mL}$, respectively.

In study 3, 31 blood samples were collected serially from each subject in each treatment period up to $72 \mathrm{~h}$ following the last morning dose. The plasma samples were assayed for amantadine using the same validated LC/MS/ MS as for study 1 .

\section{Pharmacokinetic Assessments}

Noncompartmental PK parameters were calculated for amantadine and included the maximum plasma concentration $\left(C_{\max }\right)$, time to maximum plasma concentration $\left(T_{\max }\right)$, area under the plasma concentration versus time curve (AUC) from time 0 to infinity $\left(A U C_{i n f}\right)$, apparent elimination half-life $\left(t_{1 / 2}\right)$, and apparent elimination rate constant $\left(\lambda_{\mathrm{Z}}\right)$. In studies 1 and 3 , the PK analyses were generated using Phoenix ${ }^{\circledR}$ WinNonlin ${ }^{\circledR}$ version 6.3 and Phoenix $^{\circledR}$ Connect $^{\mathrm{TM}}$ version 1.3 .1 . In study 2 , the PK analyses were generated using Phoenix ${ }^{\circledR}$ WinNonlin ${ }^{\circledR}$ version 5.3.

\section{Planned Sample Size and Statistical Analysis}

PK parameter data were summarized using descriptive summary statistics. The $90 \%$ confidence interval (CI) for the exponential of the difference in least squares (LS) means between the test and reference products was calculated for the natural-log-transformed parameters. In all studies, PK parameters were statistically analyzed using an analysis of variance model that included subject as a random effect and treatment, period, and sequence as fixed effects. In studies 1 and 3, the statistical analyses were generated using SAS ${ }^{\circledR}$ version 9.4 (mixed procedure). In study 2 , the statistical analyses were generated using $\mathrm{SAS}^{\circledR}$ version 9.3. In study 1, $C_{\max }$ and AUC were taken to be bioequivalent if the slope of a power model was within 0.80-1.25. In addition, the geometric LS mean ratio and the corresponding 90\% CIs of the dose-normalized, natural-log-transformed $\mathrm{AUC}_{\text {inf }}$ values were evaluated. 
The sample size chosen was sufficient to allow characterization of the relative bioavailability for amantadine ER tablets. No formal statistical sample size calculations were conducted, as the sample sizes were based on our estimate of the number of subjects needed to achieve the study objectives.

\section{RESULTS}

\section{Demographics and Baseline Clinical Characteristics}

In study 1, 22 of 24 enrolled subjects completed the study [two subjects discontinued due to adverse events (AEs): one subject for a urinary tract infection and one subject for decreased appetite, nausea, dizziness, headache, and vomiting]. In study 2,24 subjects completed the study. In study 3, 23 of 24 enrolled subjects completed the study (one subject discontinued due to AEs: scotomata in both eyes and muffled hearing in both ears). A summary of the demographics of all subjects who received amantadine and completed at least one study period in the three studies is presented in Table 2.

Table 2 Summary of demographics of healthy volunteers in three pharmacokinetic studies of amantadine ER tablets

\begin{tabular}{llll}
\hline Parameter & $\begin{array}{l}\text { Study 1 } \\
(\boldsymbol{N}=\mathbf{2 4})\end{array}$ & $\begin{array}{l}\text { Study 2 } \\
(\boldsymbol{N}=\mathbf{2 4})\end{array}$ & $\begin{array}{l}\text { Study 3 } \\
(\boldsymbol{N}=\mathbf{2 3})\end{array}$ \\
\hline Age (years) & $36(8)$ & $41(8)$ & $31(8)$ \\
Female, $n(\%)$ & $7(29.2)$ & $12(50.0)$ & $3(13.0)$ \\
Race, $n(\%)$ & & & \\
White & $20(83.3)$ & $13(54.1)$ & $19(82.6)$ \\
Black & $2(8.3)$ & $4(17.4)$ & $2(8.7)$ \\
Other & $2(8.3)$ & $7(29.2)$ & $2(8.7)$ \\
Weight $(\mathrm{kg})$ & $76.7(12.6)$ & $76.3(13.4)$ & $77.5(11.3)$ \\
Height $(\mathrm{cm})$ & $172.8(9.4)$ & $168.2(9.7)$ & $174.0(7.3)$ \\
Body mass & $25.6(3.0)$ & $26.8(2.3)$ & $25.6(3.0)$ \\
index $\left(\mathrm{kg} / \mathrm{m}^{2}\right)$ & & & \\
\hline
\end{tabular}

Data are presented as mean (SD) unless otherwise specified $E R$ extended-release, $S D$ standard deviation

\section{Pharmacokinetic Results}

In study 1 , following a single oral dose of an amantadine ER 129-mg, 193-mg, or 258-mg tablet, amantadine plasma concentrations increased slowly $\left(C_{\max }\right.$ values of $328.21,459.56$, and $629.52 \mathrm{ng} / \mathrm{mL}$, respectively), with a median $T_{\max }$ value of 9-9.5 $\mathrm{h}$ and a decline thereafter with a half-life of 13.2-13.8 h. By comparison, following a single oral 129-mg dose of amantadine IR syrup, amantadine plasma concentrations increased rapidly with a mean $C_{\max }$
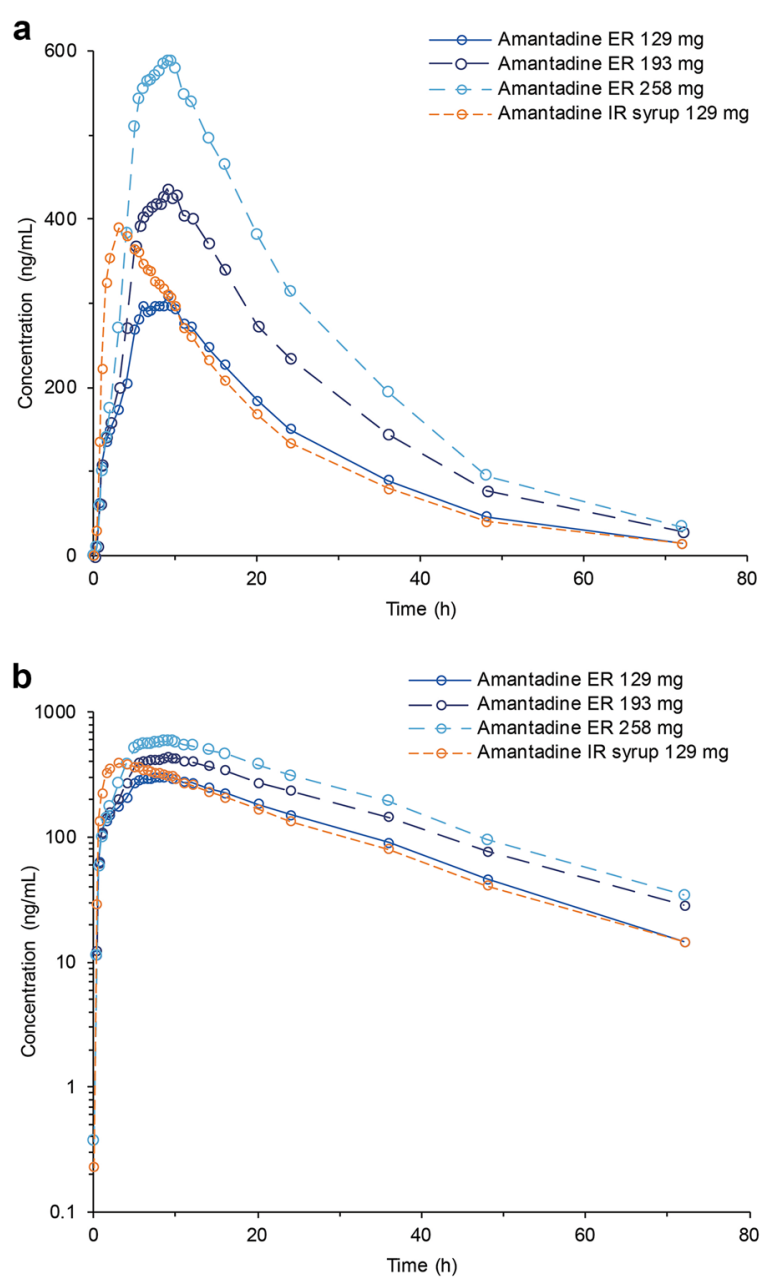

Fig. 1 Mean amantadine plasma concentration-time profile following oral administration of one $129-\mathrm{mg}, 193-\mathrm{mg}$, or 258-mg amantadine ER tablet or $129 \mathrm{mg}$ of amantadine syrup to fasted healthy volunteers in study 1 : a linear scale, b semilogarithmic scale. $E R$ extended-release, $I R$ immediate-release 
Table 3 Summary of mean pharmacokinetic parameters of amantadine following oral administration of one 129-mg, 193-mg, or 258-mg amantadine ER tablet or $129 \mathrm{mg}$ of amantadine IR syrup to fasted healthy volunteers in study 1: results

\begin{tabular}{lllll}
\hline Parameter & $\begin{array}{l}\text { Amantadine ER tablet } \\
\mathbf{1 2 9} \mathbf{~ m g}(\boldsymbol{N}=\mathbf{2 3})\end{array}$ & $\begin{array}{l}\text { Amantadine ER tablet } \\
\mathbf{1 9 3} \mathbf{~ m g}(\boldsymbol{N}=\mathbf{2 3})\end{array}$ & $\begin{array}{l}\text { Amantadine ER tablet } \\
\mathbf{2 5 8} \mathbf{~ m g}(\boldsymbol{N}=\mathbf{2 3})\end{array}$ & $\begin{array}{l}\text { Amantadine IR syrup } \\
\mathbf{1 2 9} \mathbf{~ m g}(\boldsymbol{N}=\mathbf{2 3})\end{array}$ \\
\hline $\begin{array}{l}C_{\max } \\
\quad(\mathrm{ng} / \mathrm{mL})\end{array}$ & $328.21(18.2)$ & $459.56(19.0)$ & $629.52(20.9)$ & $403.54(16.2)$ \\
$T_{\max }(\mathrm{h})^{\mathrm{a}}$ & $9.00(5.5-10.0)$ & $9.00(6.0-12.0)$ & $9.50(5.0-12.0)$ & $3.00(1.5-8.5)$ \\
$\mathrm{AUC}_{\mathrm{inf}}$ & $8580.45(19.0)$ & $13,123.64(20.4)$ & $17.705 .51(21.3)$ & $9007.72(17.8)$ \\
$\quad(\mathrm{ng} \cdot \mathrm{h} / \mathrm{mL})$ & & & & $0.0533(22.2)$ \\
$\lambda_{\mathrm{Z}}\left(\mathrm{h}^{-1}\right)$ & $0.0524(19.8)$ & $0.0501(28.1)$ & $0.0515(20.5)$ & 13.0 \\
$t_{1 / 2}(\mathrm{~h})^{\mathrm{b}}$ & 13.2 & 13.8 & 13.5 &
\end{tabular}

Data are presented as mean $(\% \mathrm{CV})$ unless otherwise specified

$\lambda_{Z}$ apparent elimination rate constant, $A U C_{\text {inf }}$ area under the plasma concentration-time curve extrapolated to infinity, $C_{\max }$ maximum observed plasma concentration, $C V$ coefficient of variation, $E R$ extended-release, $I R$ immediate-release, $t_{1 / 2}$ terminal elimination half-life, $T_{\max }$ time of maximum observed plasma concentration

a Median (range)

b Harmonic mean $t_{1 / 2}=0.693 /$ mean $\lambda_{\mathrm{Z}}$

value of $403.54 \mathrm{ng} / \mathrm{mL}$, a median $T_{\max }$ value of $3 \mathrm{~h}$ and a half-life of $13 \mathrm{~h}$ (Fig. 1 and Table 3).

Longer $T_{\max }$ and decreased $C_{\max }$ values following a single oral dose confirmed that there was a slower rate of amantadine absorption from the 129-mg amantadine ER tablet. $T_{\max }$ occurred much later ( $9 \mathrm{~h}$ postdose) for the amantadine ER tablet than for the amantadine IR syrup ( $3 \mathrm{~h}$ postdose); $C_{\max }$ for the $129-\mathrm{mg}$ amantadine ER tablet was $81.05 \%(90 \%$ CI 77.34-84.93\%) of that following the administration of amantadine IR syrup. The extent of amantadine absorption from the amantadine ER 129-mg tablet was equivalent to that from the amantadine IR 129-mg syrup. The geometric LS mean ratio of the natural-log-transformed $\mathrm{AUC}_{\text {inf }}$ was $95.27 \%$, and the $90 \%$ CI of $90.24-100.57 \%$ was within the $80.00-125.00 \%$ bioequivalence limits (Table 4 ).

Following a single oral dose of an amantadine ER tablet $(129,193$, or $258 \mathrm{mg})$, amantadine bioavailability (as reflected in the $C_{\max }$ and $\mathrm{AUC}_{\text {inf }}$ values) increased proportionally with increasing dose. Amantadine exposure increased in proportion with dose, as indicated by power model slope values of 0.92845 and 1.03767 for $\ln C_{\max }$ and $\ln A \mathrm{UC}_{\mathrm{inf}}$, respectively.
When comparing doses, the geometric LS mean ratio of the dose-normalized, natural-log-transformed $\mathrm{AUC}_{\mathrm{inf}}$ values ranged from 97.59-99.04\% with corresponding 90\% CIs between $92.03 \%$ and $105.01 \%$. These results confirm the dose proportionality across the three amantadine ER tablet doses.

In study 2 , the mean plasma concentration-time profiles of amantadine ER tablets administered under fed and fasted conditions were comparable (Fig. 2, Table 5). The geometric LS means of $C_{\max }$ and $\mathrm{AUC}_{\mathrm{inf}}$ values following single oral dose administration of $258 \mathrm{mg}$ amantadine ER tablets with and without food were equivalent (Table 6). The geometric LS mean fed/fasted ratios and $90 \%$ CIs of the natural-log-transformed $C_{\max }$ and $\mathrm{AUC}_{\mathrm{inf}}$ values were within the predefined 80.00-125.00\% limits, indicating that no significant food effect was observed (Table 6).

In study 3, following multiple-dose oral administration of the 129-mg amantadine IR syrup twice daily, plasma concentrations increased rapidly with a median $T_{\max }$ value of 2-3 h postdose ( $T_{\max 0-12}$ and $T_{\max 12-24}$ were 3 and $14 \mathrm{~h}$, respectively), declining thereafter with a mean half-life of $13.7 \mathrm{~h}$. Following 
Table 4 Summary of mean pharmacokinetic parameters of amantadine following oral administration of one 129-mg, $193-\mathrm{mg}$, or 258-mg amantadine ER tablet or $129 \mathrm{mg}$ of amantadine IR syrup to fasted healthy volunteers in study 1 : statistical analysis

\begin{tabular}{lccl}
\hline Parameter & $\begin{array}{l}\text { Amantadine ER tablet } \mathbf{1 2 9} \mathbf{~ m g}^{\mathbf{a}} \\
(\boldsymbol{N}=\mathbf{2 3})\end{array}$ & $\begin{array}{l}\text { Amantadine IR syrup } \mathbf{1 2 9} \mathbf{~ m g}^{\mathbf{a}} \\
(\boldsymbol{N}=\mathbf{2 3})\end{array}$ & $\begin{array}{l}\text { Test/reference ratio } \\
(\mathbf{9 0 \%} \mathbf{C I})\end{array}$ \\
\hline$C_{\max }(\mathrm{ng} / \mathrm{mL})$ & 321.92 & 397.21 & $81.05(77.34-84.93)$ \\
$\mathrm{AUC}$ & 8873.45 & $95.27(90.24-100.57)$ \\
$(\mathrm{ng} \cdot \mathrm{h} / \mathrm{mL})$ & 8453.50 & & \\
\hline
\end{tabular}

$A U C_{i n f}$ area under the plasma concentration-time curve extrapolated to infinity, $C I$ confidence interval, $C_{\text {max }}$ maximum observed plasma concentration, ER extended-release, $I R$ immediate-release

a Geometric least-squares mean

multiple-dose oral administration of one 258-mg amantadine ER tablet once daily, the plasma concentration of amantadine increased slowly with a median $T_{\max 0-24}$ value of $7.5 \mathrm{~h}$, declining thereafter with a mean half-life of $13.3 \mathrm{~h}$. As shown in Fig. 3, amantadine ER concentration peaks in the middle of the day (following a morning dose) and is lower than amantadine IR syrup overnight. The average concentration $\left(C_{\text {avg0-24 }}\right)$ value for 258-mg amantadine ER tablet was $947.40 \mathrm{ng} / \mathrm{mL}$, and was comparable to the value for 129 -mg amantadine IR syrup, which was $965.13 \mathrm{ng} / \mathrm{mL}$ (Table 7). $C_{\max }$ and AUC values for twice-daily amantadine IR 129-mg syrup were equivalent to those for once-daily administration of amantadine ER 258-mg tablets (Tables 7, 8). At steady state, the 258-mg amantadine ER tablet was bioequivalent to $258-\mathrm{mg} /$ day amantadine IR syrup; the $90 \%$ CI for $C_{\max }$ and AUC were within the $80.00-125.00 \%$ bioequivalence limits (Table 8).

\section{DISCUSSION}

The results of study 1 confirmed that amantadine is slowly absorbed following oral administration of amantadine ER. Amantadine plasma exposure $\left(C_{\max }, \mathrm{AUC}_{\text {inf }}\right)$ increased doseproportionally following oral administration of single doses of 129-mg, 193-mg, and 258-mg amantadine ER tablets. The extent of amantadine absorption from the 129-mg amantadine ER tablet is equivalent to that from 129-mg amantadine IR syrup $(40 \mathrm{mg} / 5 \mathrm{~mL})$.
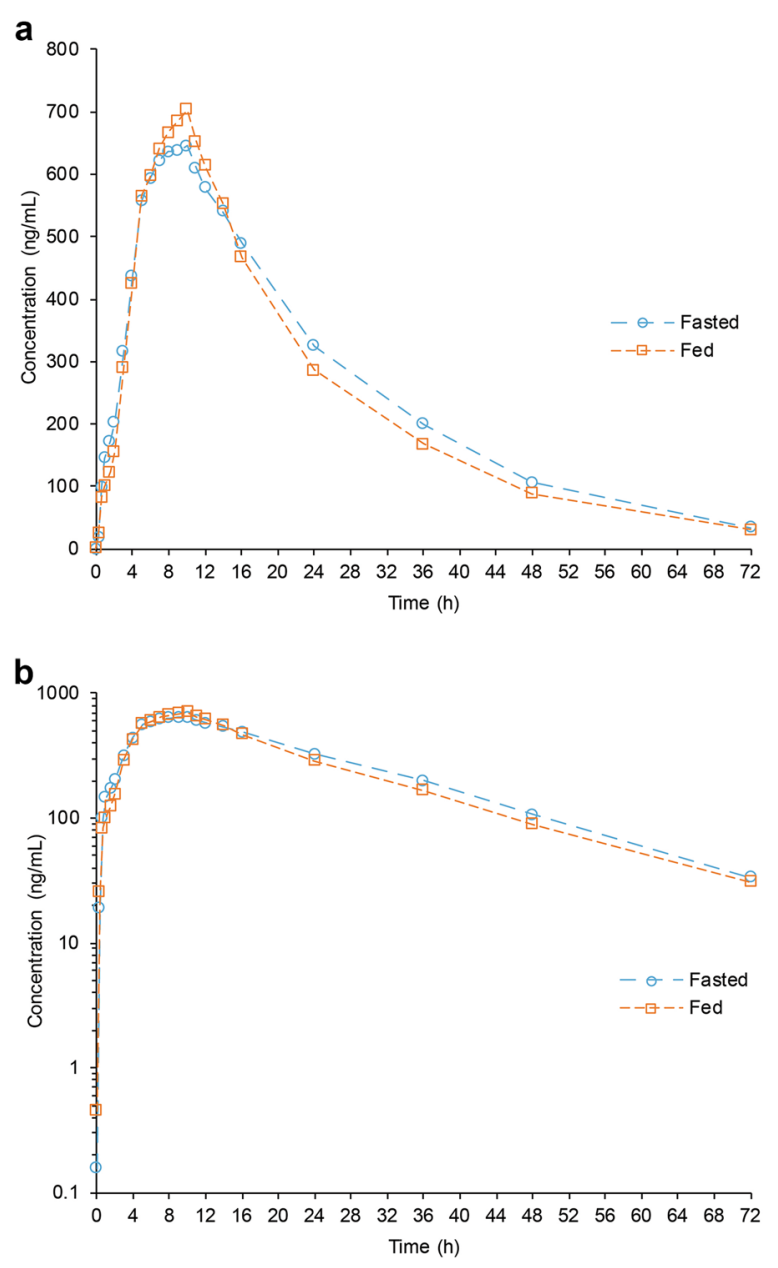

Fig. 2 Amantadine plasma concentration-time profile following oral administration of one 258-mg amantadine ER tablet under fasted (reference) or fed (test) conditions in study 2: a linear scale, b semilogarithmic scale. ER extended-release 
Table 5 Summary of amantadine relative bioavailability following single-dose, oral administration of 258-mg amantadine ER tablets under fed and fasting conditions to healthy volunteers in study 2: results

\begin{tabular}{lll}
\hline Parameter & Fed (test) $(\boldsymbol{N}=\mathbf{2 4})$ & Fasted (reference) $(\boldsymbol{N}=\mathbf{2 4})$ \\
\hline$C_{\max }(\mathrm{ng} / \mathrm{mL})$ & $726.500(23.2)$ & $667.406(18.7)$ \\
$T_{\max }(\mathrm{h})^{\mathrm{a}}$ & $9.009(5.0-10.1)$ & $9.000(5.0-10.0)$ \\
$\mathrm{AUC}_{\text {inf }}(\mathrm{ng} \cdot \mathrm{h} / \mathrm{mL})$ & $17,379.367(26.7)$ & $18,481.399(27.1)$ \\
$\lambda_{\mathrm{Z}}\left(\mathrm{h}^{-1}\right)$ & $0.053(21.2)$ & $0.053(20.6)$ \\
$t_{1 / 2}(\mathrm{~h})$ & $13.564(22.0)$ & $13.577(22.5)$ \\
\hline
\end{tabular}

Data are presented as mean $(\% \mathrm{CV})$ unless otherwise specified

$\lambda_{Z}$ apparent elimination rate constant, $A U C_{\text {inf }}$ area under the plasma concentration-time curve extrapolated to infinity, $C_{\max }$ maximum observed plasma concentration, $C V$ coefficient of variation, $E R$ extended release, $t_{1 / 2}$ terminal elimination half-life, $T_{\max }$ time of maximum observed plasma concentration

${ }^{a}$ Median (range)

Table 6 Summary of amantadine relative bioavailability following single-dose, oral administration of 258-mg amantadine ER tablets under fed and fasting conditions to healthy volunteers in study 2: statistical analysis

\begin{tabular}{llll}
\hline Parameter & Fed $(\text { test })^{\mathbf{a}}(\boldsymbol{N}=\mathbf{2 4})$ & Fasted $\left(\right.$ reference) $^{\mathbf{a}}(\boldsymbol{N}=\mathbf{2 4})$ & Test/reference ratio $(\mathbf{9 0 \%} \mathbf{C I})$ \\
\hline$C_{\max }(\mathrm{ng} / \mathrm{mL})$ & 708.2 & 655.6 & $108.0(102.5-113.9)$ \\
$\mathrm{AUC} C_{\text {inf }}(\mathrm{ng} \cdot \mathrm{h} / \mathrm{mL})$ & $16,793.8$ & $17,797.2$ & $94.4(88.8-100.2)$ \\
\hline
\end{tabular}

$A U C_{\text {inf }}$ area under the plasma concentration-time curve extrapolated to infinity, $C I$ confidence interval, $C_{\max }$ maximum observed plasma concentration

${ }^{a}$ Geometric least-squares mean

Study 2 confirmed that a high-fat meal does not affect the bioavailability of amantadine ER tablets, indicating that amantadine ER tablets may be administered irrespective of meals.

Finally, study 3 confirmed that at steady state, once-daily administration of 258-mg amantadine ER tablets is bioequivalent to twicedaily administration of 129-mg amantadine IR syrup ( $40 \mathrm{mg} / 5 \mathrm{~mL}$ ); equivalent $C_{\text {avg0-24 }}$ values following equivalent daily doses of amantadine ER tablets and amantadine IR syrup (947.40 ng/ $\mathrm{mL}$ ER and $965.13 \mathrm{ng} / \mathrm{mL}$ IR syrup) confirm that the amantadine daily exposure is equivalent for ER and IR formulations. OS320 is not interchangeable with other amantadine IR or ER products.

These studies provide a comprehensive analysis of OS320 bioavailability, including the food effect, single-dose and steady-state pharmacokinetics. The purpose of this study was to report on the plasma PK and relative bioavailability of OS320. This study does not take into consideration gender differences which may exist with amantadine PK. Many early pharmacokinetic studies relied on a solely male population, and previous work has indicated that there are gender-specific differences in amantadine IR excretion when dosed in combination with quinidine or quinine $[4,11]$. However, another study in a population of PD patients indicates that there are no genderspecific differences in efficacy [12].

Study limitations should be considered when interpreting these results. This analysis also does not include patients with renal impairment. As amantadine is primarily excreted by glomerular filtration and tubular secretion $[1,4,5]$, patients with renal impairment should 

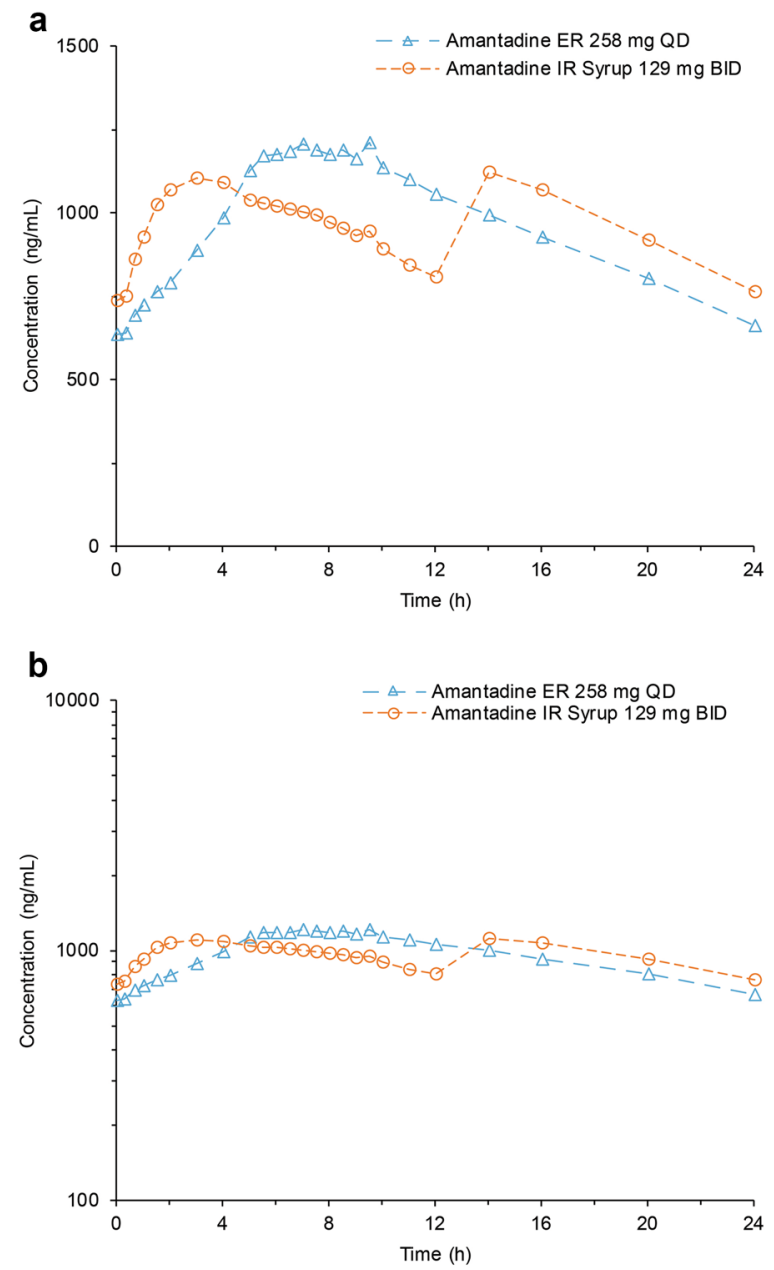

Fig. 3 Amantadine plasma concentration-time profile mean following oral administration of one 258-mg amantadine ER tablet daily or $129-\mathrm{mg}$ amantadine IR syrup twice daily for 7 days to fasted healthy volunteers in study 3: a linear scale, b semilogarithmic scale. BID twice daily, $E R$ extended-release, $I R$ immediate-release, $Q D$ once daily

be supervised closely by their physicians. The once-daily, 258-mg dose should be used with caution in elderly patients and in patients with renal impairment. Additional research is needed to determine the effect of renal impairment on OS320 pharmacokinetics.

Amantadine has been shown to have a longer half-life in brain tissue than in plasma, raising questions regarding the utility of plasma PK in predicting amantadine efficacy [13]. However, work using a different formulation of
ER amantadine (ADS-5102) concluded that plasma amantadine concentration is correlated with efficacy as measured by reduction in dyskinesia in nonhuman primates [14].

Parkinson's disease patients or patients with drug-induced EPRs whose response is not optimal with a 129-mg amantadine ER tablet once daily may benefit from an increase to an amantadine ER 193-mg tablet once daily, taken in the morning.

The results of these healthy volunteer studies are consistent with the previous data reported for amantadine. These studies demonstrated that following a single oral dose of OS320, plasma concentration increases in a dose-proportional manner. At steady state, once-daily administration of 258-mg amantadine ER tablets is bioequivalent to twice-daily administration of 129-mg amantadine IR syrup ( $40 \mathrm{mg}$ / $5 \mathrm{~mL}$ ), and absorption of OS320 relative to amantadine IR syrup is slower, leading to more stable steady-state plasma levels throughout the day when given in the morning.

\section{CONCLUSIONS}

These results support the hypotheses of these three PK studies. Study 1 confirmed that amantadine is slowly absorbed following amantadine ER oral administration in healthy adults. Study 2 confirmed that food does not have a clinically significant effect on amantadine bioavailability. Study 3 confirmed that amantadine plasma exposure increases doseproportionally with an increasing dose, and at steady state, the 24-h average amantadine plasma concentration is equivalent to that for the same daily dose of IR amantadine administered twice daily. In a clinical setting, OS320 is bioequivalent to IR amantadine and can be used in a similar manner. OS320 is not interchangeable with other amantadine IR or ER products. Prescribers should consider these factors and monitor patients when initiating therapy with OS320. 
Table 7 Mean pharmacokinetic parameters of amantadine following oral administration of one 258-mg amantadine ER tablet daily or 129-mg amantadine syrup twice daily for 7 days to fasted healthy volunteers in study 3: results

\begin{tabular}{lll}
\hline Parameter & $\begin{array}{l}\text { Amantadine ER tablet, 258 mg } \\
\text { once daily (test) }(\boldsymbol{N}=\mathbf{2 3})\end{array}$ & $\begin{array}{l}\text { Amantadine IR syrup 129 mg } \\
\text { twice daily (reference) }(\boldsymbol{N}=\mathbf{2 3})\end{array}$ \\
\hline$C_{\max 0-24}(\mathrm{ng} / \mathrm{mL})$ & $1275.01(21.6)$ & $1165.90(18.9)$ \\
$T_{\max 0-24}(\mathrm{~h})^{\mathrm{a}}$ & $7.50(5.0-12.0)$ & $14.00^{\mathrm{b}}$ \\
$\mathrm{AUC}_{0-24}(\mathrm{ng} \cdot \mathrm{h} / \mathrm{mL})$ & $22,737.52(24.7)$ & $23,163.15(22.0)$ \\
$C_{\mathrm{avg} 0-24}(\mathrm{ng} / \mathrm{mL})$ & $947.40(24.7)$ & $965.13(22.0)$ \\
$\lambda_{\mathrm{Z}}\left(\mathrm{h}^{-1}\right)$ & $0.0521(27.6)$ & $0.0505(27.3)$ \\
$t_{1 / 2}(\mathrm{~h})^{\mathrm{c}}$ & 13.3 & 13.7 \\
\hline
\end{tabular}

Data are presented as mean $(\% \mathrm{CV})$ unless otherwise specified

$\lambda_{Z}$ apparent elimination rate constant, $A U C_{0-24}$ cumulative area under the plasma concentration-time curve from 0 to $24 \mathrm{~h}$, $C_{\text {avgo-24 }} \mathrm{AUC}_{0-24} / 24 \mathrm{~h}, C_{\text {max } 0-24}$ maximum observed plasma concentration over $24 \mathrm{~h}$ after the last morning dose of each period, $C V$ coefficient of variation, $E R$ extended-release, $I R$ immediate-release, $t_{1 / 2}$ terminal elimination half-life, $T_{\text {max } 0-24}$ time of maximum observed plasma concentration over $24 \mathrm{~h}$ after the last morning dose of each period

a Median (range)

b $T_{\max }$ value for the $0-12$ and $12-24 \mathrm{~h}$ interval was 3 and $2 \mathrm{~h}$ postdose, respectively

c Harmonic mean $t_{1 / 2}=0.693 /$ mean $\lambda_{\mathrm{Z}}$

Table 8 Mean pharmacokinetic parameters of amantadine following oral administration of one 258-mg amantadine ER tablet daily or 129-mg amantadine syrup twice daily for 7 days to fasted healthy volunteers in study 3: statistical analysis

\begin{tabular}{llll}
\hline Parameter & $\begin{array}{l}\text { Amantadine ER tablet } \\
\mathbf{2 5 8} \mathbf{~ m g}^{\mathbf{a}}(\boldsymbol{N}=\mathbf{2 3})\end{array}$ & $\begin{array}{l}\text { Amantadine IR syrup } \\
\mathbf{2 5 8} \mathbf{~ m g}^{\mathbf{a}}(\boldsymbol{N}=\mathbf{2 3})\end{array}$ & Ratio (90\% CI) \\
\hline$C_{\max }(\mathrm{ng} / \mathrm{mL})$ & 1242.62 & 1143.30 & $108.69(103.66-113.96)$ \\
$\mathrm{AUC}_{0-24}(\mathrm{ng} \cdot \mathrm{h} / \mathrm{mL})$ & $22,006.46$ & $22,576.18$ & $97.48(93.20-101.95)$ \\
\hline
\end{tabular}

$A U C_{0-24}$ cumulative area under the plasma concentration-time curve from 0 to $24 \mathrm{~h}, C I$ confidence interval, $C_{\text {max }}$ maximum observed plasma concentration over $24 \mathrm{~h}$ after the last morning dose of each period, $E R$ extended-release, $I R$ immediate-release

a Geometric least-squares mean

\section{ACKNOWLEDGEMENTS}

We thank Clifford Di Lea, RPh, PharmD (Aclairo Pharmaceutical Development Group, Inc., Vienna, VA, USA) for contributing to manuscript writing and revision. We thank the subjects for their participation in this study.

Funding. Funding for the study and article processing charges were provided by Osmotica Pharmaceutical US LLC, 400 Crossing Boulevard, Bridgewater, NJ, 08807. All authors had full access to all of the data in this study and take complete responsibility for the integrity of the data and accuracy of the data analysis.

Medical Writing and/or Editorial Assistance. Medical writing and editorial support was provided by Alicia Salinero, $\mathrm{PhD}$, of AlphaBioCom, LLC (King of Prussia, PA) and funded by Osmotica Pharmaceutical US LLC (Bridgewater, NJ).

Authorship. All named authors meet the International Committee of Medical Journal Editors (ICMJE) criteria for authorship for this article, take responsibility for the integrity of 
the work as a whole, and have given their approval for this version to be published.

Disclosures. Tina deVries is an employee of Osmotica Pharmaceutical US LLC and has equity interests in Osmotica Pharmaceuticals plc, the ultimate parent company of Osmotica Pharmaceutical US LLC. Angela Dentiste is an employee of Osmotica Pharmaceutical US LLC and has equity interests in Osmotica Pharmaceuticals plc, the ultimate parent company of Osmotica Pharmaceutical US LLC. Lata Handiwala is an employee of Osmotica Pharmaceutical US LLC and has equity interests in Osmotica Pharmaceuticals plc, the ultimate parent company of Osmotica Pharmaceutical US LLC. David Jacobs is an employee of Osmotica Pharmaceutical US LLC and has equity interests in Osmotica Pharmaceuticals plc, the ultimate parent company of Osmotica Pharmaceutical US LLC.

Compliance with Ethical Standards. All studies were conducted in accordance with Good Clinical Practice as defined by the International Conference on Harmonisation, the Declaration of Helsinki, and in accordance with the ethical principles underlying European Union Directive 2001/20/EC and the United States Code of Federal Regulations, Title 21, Part 50 (21CFR50). Studies 1 and 3 received ethics committee approval from IRB Services (Aurora, Ontario, Canada). Study 2 received approval from the Optimum Ethics Review Board (Oshawa, Ontario, Canada). All participants provided written informed consent before participation.

Data Availability. The datasets generated and/or analyzed during the current study are not publicly available but are available from the corresponding author on reasonable request.

Open Access. This article is distributed under the terms of the Creative Commons Attribution-NonCommercial 4.0 International License (http://creativecommons.org/licenses/ by-nc/4.0/), which permits any noncommercial use, distribution, and reproduction in any medium, provided you give appropriate credit to the original author(s) and the source, provide a link to the Creative Commons license, and indicate if changes were made.

\section{REFERENCES}

1. Deleu D, Northway MG, Hanssens Y. Clinical pharmacokinetic and pharmacodynamic properties of drugs used in the treatment of Parkinson's disease. Clin Pharmacokinet. 2002;41(4):261-309.

2. Verhagen Metman L, et al. Amantadine as treatment for dyskinesias and motor fluctuations in Parkinson's disease. Neurology. 1998;50(5):1323-6.

3. Endo Pharmaceuticals. Prescribing information for Symmetrel $^{\circledR} \quad$ (amantadine hydrochloride, USP) tablets and syrup. Dublin: Endo Pharmaceuticals; 2009.

4. Aoki FY, Sitar DS. Clinical pharmacokinetics of amantadine hydrochloride. Clin Pharmacokinet. 1988;14(1):35-51.

5. Horadam VW, et al. Pharmacokinetics of amantadine hydrochloride in subjects with normal and impaired renal function. Ann Intern Med. 1981;94(4 pt 1):454-8.

6. Muller $\mathrm{T}$, et al. Intravenous application of amantadine and antiparkinsonian efficacy in Parkinsonian patients. J Neural Transm Suppl. 1995;46:407-13.

7. Somani SK, et al. Comparison of pharmacokinetic and safety profiles of amantadine 50- and 100-mg daily doses in elderly nursing home residents. Pharmacotherapy. 1991;11(6):460-6.

8. Vargus-Adams JN, et al. Pharmacokinetics of amantadine in children with impaired consciousness due to acquired brain injury: preliminary findings using a sparse-sampling technique. PM R. 2010;2(1):37-42.

9. Morrison D, et al. A randomized, crossover study to evaluate the pharmacokinetics of amantadine and oseltamivir administered alone and in combination. PLoS One. 2007;2(12):e1305.

10. Vertical Pharmaceuticals, LLC. Prescribing information for OSMOLEX $\mathrm{ER}^{\mathrm{TM}}$ (amantadine) extended-release tablets. Bridgewater, NJ: Vertical Pharmaceuticals, LLC; 2018.

11. Fletcher CV, Acosta EP, Strykowski JM. Gender differences in human pharmacokinetics and pharmacodynamics. J Adolesc Health. 1994;15(8):619-29. 
12. Parkes JD, et al. Amantadine dosage in treatment of Parkinson's disease. Lancet. 1970;1(7657):1130-3.

13. Kornhuber J, et al. Pharmacokinetic characterization of amantadine in human brain tissue. Ther Drug Monit. 2006;28(5):693-5.
14. Brigham EF, et al. Pharmacokinetic/pharmacodynamic correlation analysis of amantadine for levodopa-induced dyskinesia. J Pharmacol Exp Ther. 2018;367(2):373-81. 